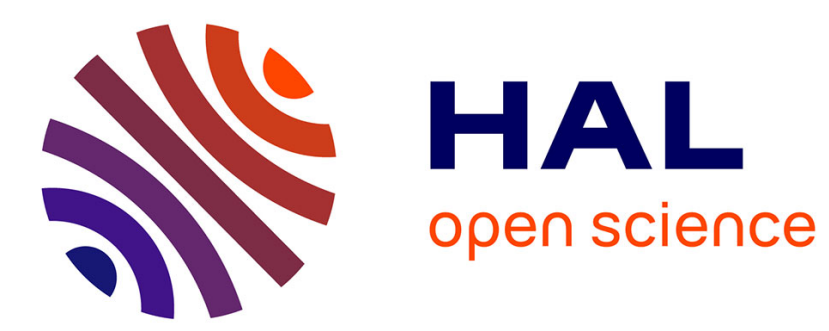

\title{
Confinement and flow dynamics in thin polymer films for nanoimprint lithography
}

\author{
J. Teisseire, E. Revaux, M. Foresti, E. Barthel
}

\section{To cite this version:}

J. Teisseire, E. Revaux, M. Foresti, E. Barthel. Confinement and flow dynamics in thin polymer films for nanoimprint lithography. Applied Physics Letters, 2011, 98, pp.013106. 10.1063/1.3535614 . hal-00553474

\section{HAL Id: hal-00553474 \\ https://hal.science/hal-00553474}

Submitted on 10 Jan 2011

HAL is a multi-disciplinary open access archive for the deposit and dissemination of scientific research documents, whether they are published or not. The documents may come from teaching and research institutions in France or abroad, or from public or private research centers.
L'archive ouverte pluridisciplinaire HAL, est destinée au dépôt et à la diffusion de documents scientifiques de niveau recherche, publiés ou non, émanant des établissements d'enseignement et de recherche français ou étrangers, des laboratoires publics ou privés. 


\title{
Confinement and flow dynamics in thin polymer films for nanoimprint lithography
}

\author{
Jérémie Teisseire, Amélie Revaux, Maud Foresti, and Etienne Barthel ${ }^{\mathrm{a})}$ \\ Surface du Verre et Interfaces, UMR 125 CNRS/Saint-Gobain, 39 quai Lucien Lefranc, BP 135, F-93303 \\ Aubervilliers Cedex, France
}

(Received 6 July 2010; accepted 17 December 2010; published online 6 January 2011)

\begin{abstract}
In nanoimprint lithography (NIL) viscous flow in polymeric thin films is the primary mechanism for the generation and the relaxation of the structures. Here we quantify the impact of confinement on the flow rate. Pattern relaxation experiments were carried out above the glass transition temperature as a function of film thickness. The results are adequately fitted by a simple expression for the flow rate valid at all confinements. This expression, based on Newtonian viscosity, should be of use in NIL process design and for the measurement of the rheological properties of confined polymers.

(C) 2011 American Institute of Physics. [doi:10.1063/1.3535614]
\end{abstract}

Surface textures offer an interesting paradigm for advanced properties in the areas of optics, ${ }^{1}$ adhesion, ${ }^{2}$ and wetting. ${ }^{3}$ Efficient processes must be found for fast and low cost production of elaborate surface textures on large substrates. Nanoimprint lithography (NIL) potentially fulfills these requirements. ${ }^{4-9}$ When pressing a textured mold onto a soft film (resist) deposited on the surface, the film material flows into the mask features. If the system is crosslinked or quenched before the mold is released, permanent surface features are obtained. Material flow in viscous thin films is the primary mechanism for the generation and the relaxation of the structures.

The effect of confinement on the flow in thin films is twofold. On the one hand it has been demonstrated that the intrinsic rheological properties of polymers may be altered by confinement due to modifications of structure of the material close to interfaces. ${ }^{10-14}$ On the other hand, confinement will also directly impact the flow pattern. This parameter is prominent in a number of numerical studies of embossing ${ }^{15,16}$ but there is still a good deal of confusion over this issue. On the one hand, some studies of NIL reflow ${ }^{17,18}$ completely neglect the direct impact of confinement on flow rate. On the other hand a model has recently been developed, based on the lubrication approximation ${ }^{19}$ but its validity in realistic cases has not been assessed. In this paper we measure the impact of confinement on the reflow of structures imprinted on a low molecular weight polymer and propose a simple analytic model valid in all confinement regimes to account for the data.

The experiments were carried out on poly(methyl methacrylate) (PMMA) (Sigma-Aldrich, St Quentin Fallavier) $\left[\mathrm{M}_{w}=15 \mathrm{~kg} / \mathrm{mol}\right.$, entanglement molecular weight $\left(\mathrm{M}_{e}\right.$ $=10 \mathrm{~kg} / \mathrm{mol}$ ), bulk $\left.\mathrm{T}_{g}=96{ }^{\circ} \mathrm{C}\right]$. The bulk viscosity was measured on macroscopic pellets by oscillatory frequency sweep and strain sweep $\left(\eta_{\text {bulk }}=1.2 \times 10^{7} \mathrm{~Pa}\right.$ s at $120^{\circ} \mathrm{C}$ and $4.5 \times 10^{5} \mathrm{~Pa}$ s at $130{ }^{\circ} \mathrm{C}$ ). Thin films were spin-coated onto clean $\mathrm{Si}(100)$ wafers. Thicknesses $H(0.2,0.3,0.4,1.0,1.4$, and $2.0 \mu \mathrm{m}$ ) were adjusted by dilution in methyl-isobutylketone. The residual stresses and residual solvent in the film were minimized by annealing at $170{ }^{\circ} \mathrm{C}$ during $20 \mathrm{~min}$ and cooling down to room temperature in $4 \mathrm{~h}$. A rectangular grat-

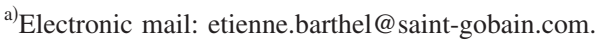

ing (wavelength $\lambda \equiv 2 \pi / k=1.5 \mu \mathrm{m}$, amplitude $2 h_{0}=50 \mathrm{~nm}$ ) was generated by nanoimprint lithography using a $1 \mathrm{~cm}^{2}$ polydimethylsiloxane (PDMS) stamp. The stamp was applied on the film with a $50 \mathrm{~N}$ load, and imprint was carried out at $170{ }^{\circ} \mathrm{C}$ for $1 \mathrm{~h}$ before cooling to room temperature in $15 \mathrm{~min}$. The stamp was easily removed from the surface of the film. Atomic force microscopy (AFM) scans of the surfaces attest that the amplitude of the replica is equal to the mask feature amplitude. We then measured the relaxation rate of the structures at constant temperature (above the glass transition temperature $T_{g}$ ) as a function of film thickness. Series of samples were annealed at $T_{r}=120{ }^{\circ} \mathrm{C}$ or $T_{r}$ $=130{ }^{\circ} \mathrm{C}$ and quenched to room temperature at regular intervals. The final profiles were measured by AFM (Fig. 1). We found that the modulation amplitude decreases exponentially as observed previously ${ }^{17,18,20}$ and that the relaxation rate decreases strongly when the thickness of the layer decreases.

The driving force for relaxation is the Laplace pressure due to the curvature of the surface with surface tension $\gamma$. For small modulation amplitude $h(t) \sin (k x)$ the modulation is expected to decrease exponentially with rate $\tau^{-1}$, which is consistent with the observations. For a half-space (unconfined relaxation) it is found ${ }^{12}$ that

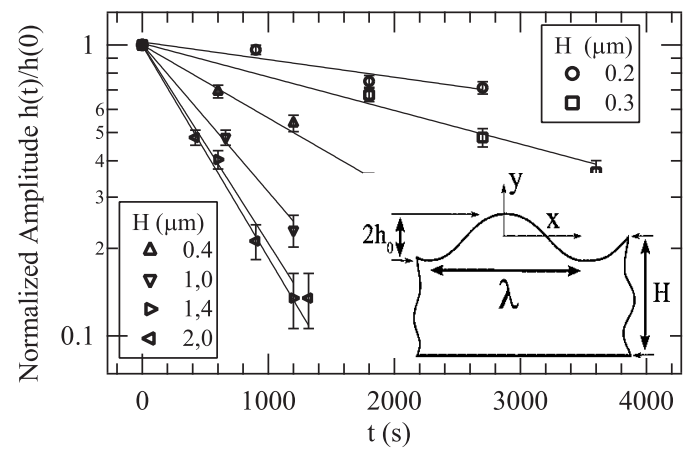

FIG. 1. Decay of structure amplitude $2 h$ as a function of annealing time for various film thicknesses. The amplitudes are normalized by the initial value $2 h(0)=50 \mathrm{~nm}$. The annealing temperature is $T_{r}=120^{\circ} \mathrm{C}$. The straight lines are exponential fits from which the relaxation rate as a function of film thickness is derived. 


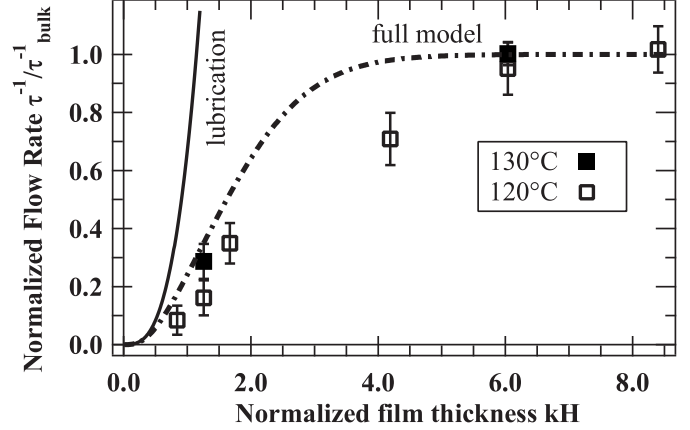

FIG. 2. Normalized flow rate measured in relaxation experiments performed at $T_{r}=120{ }^{\circ} \mathrm{C}$ (open square) and at $T_{r}=130{ }^{\circ} \mathrm{C}$ (closed square) are plotted as a function of normalized film thickness. Models: lubrication approximation [Eq. (2), plain line] and full confinement model [Eq. (3), dashed line].

$$
\tau_{\infty}^{-1}=\frac{\gamma k}{2 \eta} .
$$

To account for the marked drop of the relaxation rate with decreasing film thickness, we considered the lubrication approximation ${ }^{19}$ which predicts a very sharp reduction of the relaxation rate $\tau_{\text {lub }}^{-1}$ with confinement

$$
\tau_{\text {lub }}^{-1}=\frac{3}{2}(k H)^{3} \tau_{\infty}^{-1} .
$$

Figure 2 compares the measured relaxation rates as a function of normalized film thickness $k H$ for annealing temperatures equal to $T_{r}=120$ and $130{ }^{\circ} \mathrm{C}$ with the predictions from the lubrication approximation, which demonstrates that a more complete model is needed. Following Huang, ${ }^{21}$ we have developed a two-dimensional model assuming Newtonian viscosity. No-slip boundary conditions at the interface with the solid were assumed due to strong anchoring of PMMA on the silicon surface. ${ }^{22,23}$ For arbitrary confinement, the relaxation rate is found to scale down from the unconfined relaxation rate $\tau_{\infty}^{-1}$ as $\tau^{-1}=\mathcal{R}(k H) \tau_{\infty}^{-1}$, where

$$
\mathcal{R}(k H)=\frac{\exp (2 k H)-\exp (-2 k H)-4 k H}{\exp (-2 k H)+2+\exp (2 k H)+4(k H)^{2}},
$$

which is typical for two interacting parallel interfaces. ${ }^{24,25} \mathrm{In}$ the half-space limit $\mathcal{R}(k H)$ goes to 1 (unconfined) while Eq. (2) is recovered for small $k H$.

Comparing Eq. (2) and Eq. (3) (Fig. 2), we find that the lubrication approximation is valid for small wave vectors $k H<0.3$, i.e., for feature periods large compared to the film thickness $H<\lambda / 20$. For a less severe confinement the relaxation rate grows more slowly than $(k H)^{3}$ finally saturating at the unconfined limit $\tau_{\infty}^{-1}$ when $3<k H$ (or $\left.\lambda<2 H\right)$. $\mathcal{R}(k H)$ fits our data reasonably well with no other adjustable parameter than the unconfined flow rate [Eq. (1)]. Using a surface tension $^{26} \quad \gamma=41 \mathrm{~mJ} \mathrm{~m}^{-2}$ we infer viscosities $\eta_{\text {relax }}=5.2$ $\times 10^{7} \mathrm{~Pa}$ s for PMMA at $120^{\circ} \mathrm{C}$ and $\eta_{\text {relax }}=6.0 \times 10^{6} \mathrm{~Pa} \mathrm{~s}$ at $130{ }^{\circ} \mathrm{C}$.

Reasonably good agreement is obtained although the reduction of the flow rate in the confined regime is somewhat more progressive than the simple Newtonian fluid prediction. We note that the material viscosity evaluated from the fit, which mainly reflects the flow rate in the thick film limit $k H \gg 1$, is one order of magnitude higher than the measured bulk viscosity, quite similar to other literature results. ${ }^{27} \mathrm{Al}-$ though the $\mathrm{T}_{g}$ of such thick films is not expected to be affected by interface effects, ${ }^{10,14}$ film material may differ from

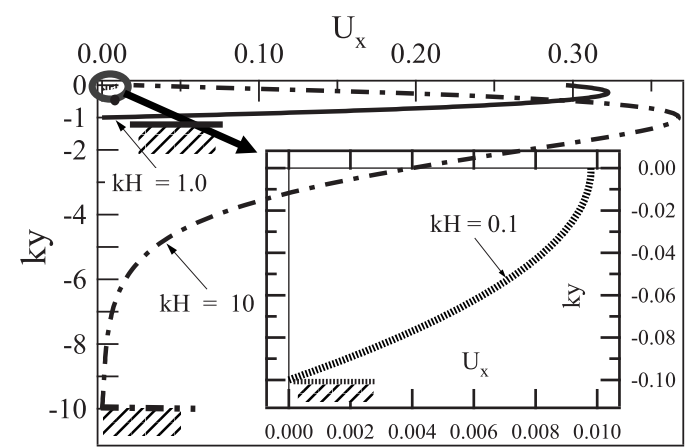

FIG. 3. Horizontal component of the velocity profile at $x=0$ for unconfined flow $(k H=10)$, intermediate confinement $(k H=1)$, and confined flow $(k H$ $=0.1$, inset). The flow profiles directly illustrate the transition between half space flow distribution with penetration depth of the order of the pattern period to the parabolic profile characteristic of the lubrication approximation.

bulk due to fast drying conditions during spin coating, short annealing time ${ }^{28}$ and possible impact of the embossing process, such as diffusion of the smaller PMMA molecules in the PDMS stamp. However the differences between films should be limited, so that it is the thickness variation which primarily impacts the flow rate and Eq. (3) provides an adequate approximation for the impact of confinement as shown on Fig. 2.

Impact of confinement can be visualized on representative horizontal velocity profiles taken at $x=0$ where the horizontal component of the velocity is maximum (Fig. 3). For large values of $k H$ (here for $k H=10$ ) the flow extends into the film over a penetration depth commensurate with the period $\lambda$ and the interface does not impact the flow distribution. Confinement (here for $k H=1$ ) results in a marked distortion of the flow, pushing the flow maximum to the surface and resulting in a drop of the flow rate (Fig. 2). Severe confinement $(k H=0.1)$ results in the quadratic in-plane velocity distribution characteristic of the lubrication approximation. We insist that the relevant measure of confinement is the ratio of the feature wavelength to the film thickness $(k H)^{-1}$. In contrast, the structure amplitude $h(0)$ does not impact the relaxation rate at this level of modeling.

As a conclusion, we have demonstrated that direct confinement effects on the flow pattern can be taken into account in flow rate prediction using a simple analytic formula for the flow rate. This equation holds for all degrees of confinement, including many realistic NIL configurations. The model has been validated through flow rate measurements as a function of film thickness. It may be used for flow rate assessment both for structure stability against reflow and for material flow into the structures during embossing or to identify dominant flow modes. ${ }^{16}$ In another area, it may also be of use for the assessment of the rheological properties of very thin polymeric films per se.

We thank Stéphane Roux, Elin Søndergård, and Aurélie Papon for suggestions and help, and the EU FP7 NapaNIL project (Contract No. NMP2-LA-2008-214249) for funding.

${ }^{1}$ S. B. Rim, S. Zhao, S. R. Scully, M. D. McGehee, and P. Peumans, Appl. Phys. Lett. 91, 243501 (2007).

${ }^{2}$ M. Lamblet, E. Verneuil, T. Vilmin, A. Buguin, P. Silberzan, and L. Leger, Langmuir 23, 6966 (2007).

${ }^{3}$ A. Tuteja, W. Choi, J. Mabry, G. McKinley, and R. Cohen, Proc. Natl. Acad. Sci. U.S.A. 105, 18200 (2008). 
${ }^{4}$ S. Chou, P. Krauss, and P. Renstrom, Appl. Phys. Lett. 67, 3114 (1995).

${ }^{5}$ G. Cross, J. Phys. D 39, R363 (2006).

${ }^{6}$ L. J. Guo, Adv. Mater. (Weinheim, Ger.) 19, 495 (2007).

${ }^{7}$ H. Schift, J. Vac. Sci. Technol. B 26, 458 (2008).

${ }^{8}$ C. Peroz, C. Heitz, E. Barthel, E. Søndergård, and V. Goletto, J. Vac. Sci. Technol. B 25, L27 (2007).

${ }^{9}$ C. Peroz, V. Chauveau, E. Barthel, and E. Sondergard, Adv. Mater. (Weinheim, Ger.) 21, 555 (2009).

${ }^{10}$ J. A. Forrest, K. Dalnoki-Veress, and J. R. Dutcher, Phys. Rev. E 56, 5705 (1997).

${ }^{11}$ M. Hamdorf and D. Johannsmann, J. Chem. Phys. 112, 4262 (2000).

${ }^{12}$ K. Petersen and D. Johannsmann, J. Non-Cryst. Solids 307-310, 532 (2002).

${ }^{13}$ M. Mundra, S. Donthu, V. Dravid, and J. Torkelson, Nano Lett. 7, 713 (2007).

${ }^{14}$ Z. Fakhraai and J. A. Forrest, Science 319, 600 (2008).

${ }^{15}$ H. D. Rowland and W. P. King, J. Micromech. Microeng. 14, 1625 (2004).

${ }^{16}$ H. D. Rowland, A. C. Sun, P. R. Schunk, and W. P. King, J. Micromech.
Microeng. 15, 2414 (2005).

${ }^{17}$ Y. Ding, H. W. Ro, T. Germer, J. Douglas, B. Okerberg, A. Karim, and C. Soles, ACS Nano 1, 84 (2007).

${ }^{18}$ Y. Ding, H. W. Ro, J. Douglas, R. Jones, D. Hine, A. Karim, and C. Soles, Adv. Mater. (Weinheim, Ger.) 19, 1377 (2007).

${ }^{19}$ T. Leveder, S. Landis, and L. Davoust, Appl. Phys. Lett. 92, 013107 (2008).

${ }^{20}$ H.-G. Peng, Y. P. Kong, and A. F. Yee, Macromolecules 43, 409 (2010).

${ }^{21}$ R. Huang and Z. Suo, Int. J. Solids Struct. 39, 1791 (2002).

${ }^{22}$ J. Keddie, R. Jones, and R. Cory, EPL 27, 59 (1994).

${ }^{23}$ L. Xue and Y. Han, Langmuir 25, 5135 (2009).

${ }^{24}$ A. Perriot and E. Barthel, J. Mater. Res. 19, 600 (2004).

${ }^{25}$ E. Barthel, A. Perriot, A. Chateauminois, and C. Frétigny, Philos. Mag. 86, 5359 (2006).

${ }^{26} \mathrm{~S}$. Wu, Polymer Interface and Adhesion (Marcel Dekker, New York, 1982).

${ }^{27}$ R. Jones, T. Hu, C. Soles, E. Lin, R. Reano, S. Pang, and D. Casa, Nano Lett. 6, 1723 (2006).

${ }^{28}$ D. Barbero and U. Steiner, Phys. Rev. Lett. 102, 248303 (2009). 